\title{
Parameters of the knife-drum type device for separating sweet corn cobs
}

\author{
Sergey K. Papusha*, Nikolay A. Nikitenko, and Valeria V. Zhadko \\ Federal State Budgetary Educational Institution of Higher Education «Kuban State Agrarian \\ University named after I.T. Trubilin» Krasnodar, Russia
}

\begin{abstract}
The paper considers issues related to the application of the knife-drum type parameters design in order to increase the productivity of the maize harvesters in the phase of milk-wax ripeness. In this regard, energy-saving technologies are required. This device allows you to reduce the percentage of loss and injury of sweet corn grains due to the absence of pressure on the cob.
\end{abstract}

Currently, the situation in agriculture in our country involves full or partial import substitution, which in turn should ensure the food security of our country, as well as protect it from a shortage of agricultural equipment.

One of the tasks of the agricultural business is the introduction of energy-saving technologies for agricultural production using a modern complex of machines, eco-friendly and waste-free use of the entire crop in the production cycle of crop production and animal husbandry, argument for the distribution of agricultural crops by natural reserves.

The implementation of waste-free technologies will require the formation of reasonable innovative ergonomic machine-tractor complexes, as well as the use of economical harvesting equipment [1].

To reduce economic costs, as well as to improve the quality of separation of corn cobs from the stalk, certainly it is necessary to start with improving the technological process of harvesting in terms of replacing the usual separation of the cob by the cutting process.

Mechanical damage to sweet corn kernels during harvesting by combines causes a decrease in the gross grain harvest, deterioration of storage, increase in irreversible losses and productive qualities of canned corn. Mechanical damage to the cobs negatively affects the taste and organoleptic characteristics of the finished product.

Even the presence of $10 \%$ of injured seeds in the harvested material leads to a deterioration in quality, mainly due to the lack of full compliance of the working bodies of harvesting machines and the physical and mechanical properties of the harvested crops, which reduces the yield by more than $1 \mathrm{c} / \mathrm{ha}$.

Agrotechnical requirements for the process of harvesting corn cobs in the phase of milkwax ripeness, in which sweet corn intended for canning is removed, damage to the grains in the cobs during separation, transportation and storage should be less than 2-3\% for canning and no more than $1 \%$ when harvesting in the cobs for sale in fresh form [2].

\footnotetext{
* Corresponding author: serega0318@mail.ru
} 
One example of the formation of economically sound solutions is the development of small-scale farming in rural areas. Currently, farms with the area of harvested crops are quite a lot in Kuban and they all need to use universal combines equipped with replaceable working bodies.

Modern devices have a number of significant disadvantages in their design for separating the cobs from the stalk, but this problem can be solved with the use of knifedrum type devices for separating sweet corn cobs. At the same time, the use of this type of apparatus can reduce the energy intensity of the separation process.

Therefore, to increase the productivity of the combine when harvesting corn, it was decided to modernize the separation device, which can be installed on various reapers of modern grain or forage harvesters [3].

A variant of the design of the device for separating cobs is proposed, which is an apparatus consisting of an infinite chain conveyor on which drum-type knives are installed with a notch similar to the segments of the cutting devices of grain harvesters. These knives, moving along the guides located on both sides of the axis of the row, form ring cells around the removed plant. After closing the cells, the cob is separated by actively rotating knives driven from a separate chain drive (Fig. 1).

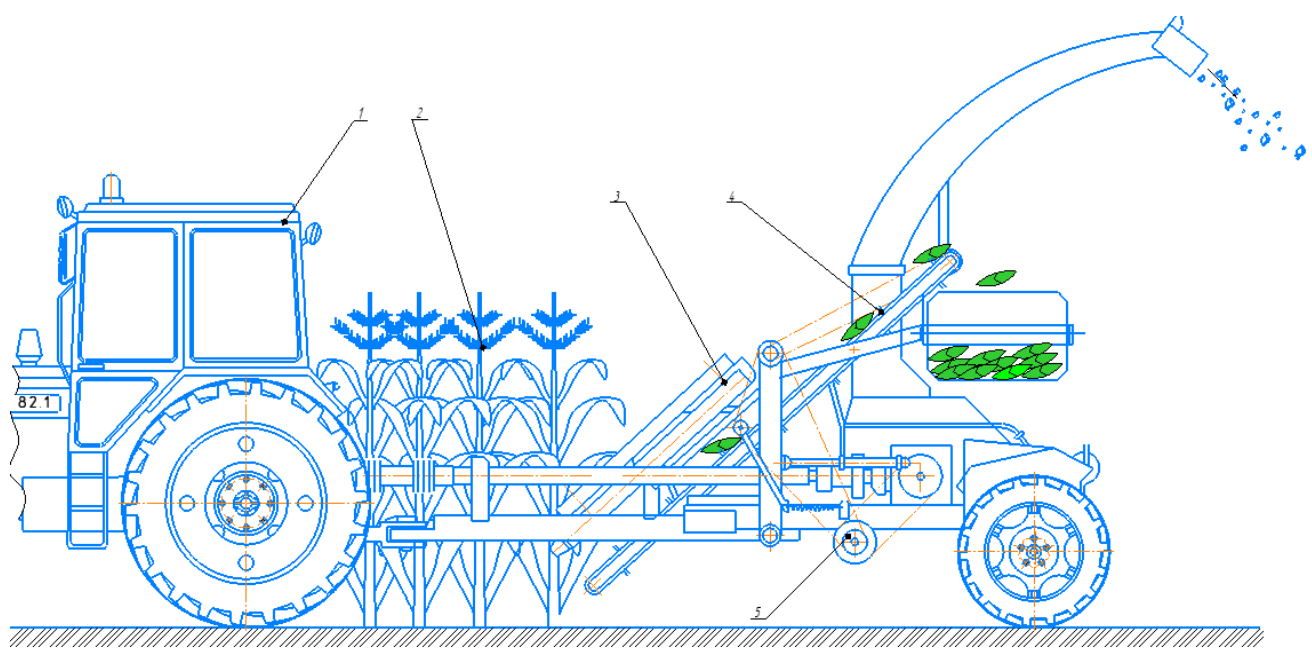

Fig. 1. Technological diagram of operation of the upgraded harvester. 1 - Harvester; 2 - corn plant; 3 - cob separator; 4 - transporter; 5 - drive gear

The drive of the knives can be carried out from a drive gearbox of various types or with the help of a hydrometer.

The forage harvester upgraded in this way works as follows.

When the harvester moves along the row of plants being removed, the dividers bring the stalks to the working channel, where a modernized cob-separating device is installed. A cutting device installed under the working contour cuts the plants being removed. Then they are held by rollers, accompanied until the moment of separation of the cob from the stalk.

After separating the cob, the mown stalks fall into the shredder of the forage harvester, where they are subsequently crushed with knives and loaded into the vehicle via a silo pipe.

At this time, the cobs separated from the stalk fall on the conveyor with the blades installed on it. These blades transfer the separated sweet corn cobs to a pitched board, which is blown by an air stream created by a fan. In this case, the pile of cobs is cleared of the leaf-stalk mass, which has separated along with the cob. Then this mass enters the shredder through the loading screw, and the peeled cobs are loaded into the hopper. 
The transmission of the device and conveyors are driven by a hydraulic motor, and the shredder is driven by a drive gear connected to the tractor's PTO. This allows you to reconfigure the harvester for harvesting other crops quickly [4].

The main need for harvesting sweet corn is to reduce grain losses, cleaning costs and other works. In parallel with the cleaning, measures should be taken to obtain finished raw materials and sell them. Also, to reduce costs at the stage of corn harvesting, it can be implemented by collecting a by-product, such as leaf-stem mass. The leaf-stem mass can be further used for the production of silage and used as a highly nutritious feed for farm animals. This determines the cost of the crop, and the increase in economic effect is possible only with the use of reproductive harvesting machines that allow you to meet the strict agrotechnical deadlines for harvesting.

The task of the knife-drum type device is to separate the sweet corn cobs from the stalk by cutting using an active rotating drum-type knife due to a chain drive. The relevance of this solution is obvious, since the use of this separation scheme will reduce the percentage of injured grains in the cob due to the lack of pressure on the lower part of the cob. Replacing the separation with cutting will also reduce energy costs and thus increase productivity, since the power reserves released during the separation process can be directed to the operation of the combine.

The use of an improved knife-drum type device for separating sweet corn cobs will reduce grain losses due to the preservation of grains, and, consequently, will increase the quality and, accordingly, the price of sales of products.

Timely investment in improving the knife-drum type apparatus for separating sweet corn cobs will be highly effective.

\section{References}

1. Mashtalir A. N. Reducing production costs when harvesting sugar corn / A. N. Mashtalir, S. K. Papusha / In the collection: Scientific support of the agro-industrial complex Collection of articles based on the materials of the IX All-Russian conference of young scientists. Chief editor: A. G. Koshchayev. / Krasnodar - 2016. p. 368-369.

2. Papusha S. K., Theoretical study of the process of separating the tobacco leaf from the stalk / S. K. Papusha, E. I. Vinevsky, V. I. Konovalov, S. I. Konovalov, O. A. Sterligov // Polythematic network electronic scientific journal of Kuban State Agrarian University. 2017. \# 126. P. 289-303.

3. Papusha S. K. Justification of parameters and modes of operation of the universal working body of the roller type for harvesting high-stalked crops (for example, tobacco). // abstract of PhD thesis / Don State Technological University. Rostov-onDon, 2017.

4. Patent 2312486 Russian Federation, IPC A01D 45/16. Apparatus for separating tobacco leaves [Text] / S. K. Papusha, E. I. Vinevsky, A. E. Lysenko, I. B. Poyarkov, I. I. Dyachkin; applicant and patentee of GNU VNIITTI.\# 2006119254/12; claimed 01.06.2006; publ. 20.12.2007. Bul.\# 35.- p.5: illust. 